if a committee and the agency which it is supposed to superintend live too closely in each other's pockets, there will be no means of making sure that their combined attitude to the outside world is sound. Another is that a committee which is too knowledgeable and too winsome may find itself persuading a government agency to particular lines of development which become, in retrospect, unwise. In other words, there is a danger that too expert a committee might find itself able to exercise power without responsibility.

On the face of things, the Joint Committee tends towards errors of the second kind. Its report on this year's budget application by the AEC (see page 116) shows how carefully the committee picks over the details of the budget, subtracting a few thousand dollars here and there, and sometimes even adding a few thousand. On one view, this is a splendid illustration of the democratic control of public institutions. On another, it is a sign that Congress and the Administration are too closely entangled.

There is no reason to believe that the committee's work has been unreasonably intrusive in the recent past. On the contrary, the chances are that the prodding needed to make accurate calculations of the cost of running particle accelerators before constructing them, and the campaign for better regulations to protect the health of uranium miners, have helped to make the policies of the AEC more sensible. But what if the question should arise of whether the AEC in its present form should continue to exist? Would the Joint Committee take kindly even to the much more modest proposal that responsibility for high energy physics might be transferred to the National Science Foundation? There is bound to be a suspicion that the Joint Committee, for all its expertise, would resist too radical a change. The trouble is that the time has probably come for a detailed re-examination of the function of the AEC. The best proof the committee could give of its resolution would be to begin an investigation off its own bat.

\section{PINK SPOTS GALORE}

Iт is now five years since Friedhoff and Winkle first suggested that the urine of schizophrenic patients may be characterized by something which yields a pink spot in a fairly standard chromatographic procedure (Nature, 194, 897; 1962) and the interval has been crowded with ups and downs. At the beginning, of course, there was great excitement. The finding of the pink spot chimed in well with an accumulation of evidence to suggest that the metabolism of schizophrenic patients is biochemically distinctive. Five years ago, however, it must have seemed almost too much to hope for that the appearance of a single chemical substance, identifiable by a comparatively simple technique, might serve to distinguish a substantial proportion-ten per cent or so--of those who suffer from schizophrenia. Obviously a simple pink spot would have great value in diagnosis, although this was almost the least exciting of many possibilities. Naturally enough there was talk of seeking out people who might be biochemically prone to schizophrenia, but in whom the symptoms had not become overt. But there was also every reason to hope that when the chemical responsible for the pink spot had been properly identified, a means would have been provided for understanding something of the biochemical character of schizophrenia, and possibly of its causation as well. No wonder, then, that hats were thrown in the air when, in 1963, it seemed as if the chemical responsible for the pink spot might be $\beta$-3,4-dimethoxyphenylethylamine, or DMPE for short, for it is entirely plausible that such a chemical could have arisen by an error of tyrosine metabolism and that its pharmacological effect might be something like schizophrenia.

Those happy days now seem a long way off. Doubts about the identification of the pink spot with DMPE persisted from the beginning. One difficulty is the obvious problem of working with tiny quantities of material. In circumstances like these, chemical identification is necessarily rather indirect. But there were more serious problems bound up with the difficulties of knowing whether subjects examined for pink spot in the urine were schizophrenic or otherwise, for this is not a field in which diagnosis is easy. Predictably it was not long before apparently normal people were found to yield pink spot. Yet another difficulty was that the substance responsible might be produced by the metabolism of some drug used in the treatment of patients. Finally, a year ago it was demonstrated more or less conclusively that whatever pink spot might be, it was certainly not DMPE. The tale has now taken another turn with the report that the substance responsible is probably $p$-tyramine, and that the material which is responsible for the schizophrenic pink spot also occurs in urine from many patients with Parkinson's disease (see this issue, page 132). Boulton, Pollitt and Majer seem to be quite confident that the pink spots they have been able to find in the urine of patients with schizophrenia and Parkinson's disease are caused by $p$-tyramine. With the benefit of hindsight, it now seems likely that the schizophrenic pink spots reported in recent years may often have been caused by $p$-tyramine and not DMPE. Moreover, while the difficulties of diagnosis must still leave doubt about the association of the pink spot with schizophrenia, it is much more probable that it is causally related to Parkinson's disease. Already speculation has begun about the ways in which errors of metabolism in parkinsonism may account not merely for the $p$-tyramine but for the abnormally high concentrations of dopamine in some brain tissues from patients with Parkinson's disease. The suggestion that there may be a biochemical link between some forms of schizophrenia and Parkinson's disease will not come as a complete surprise. This said, it is bound of course to be a long time before the precise significance of the pink spot is clear, but it is something important gained if its chemical identity is now assured. 